\title{
Software Verification and Validation Plan Activities, 2011 - SAPHIRE 8 Quality Assurance
}

Kurt G. Vedros

Curtis L. Smith

September 2011
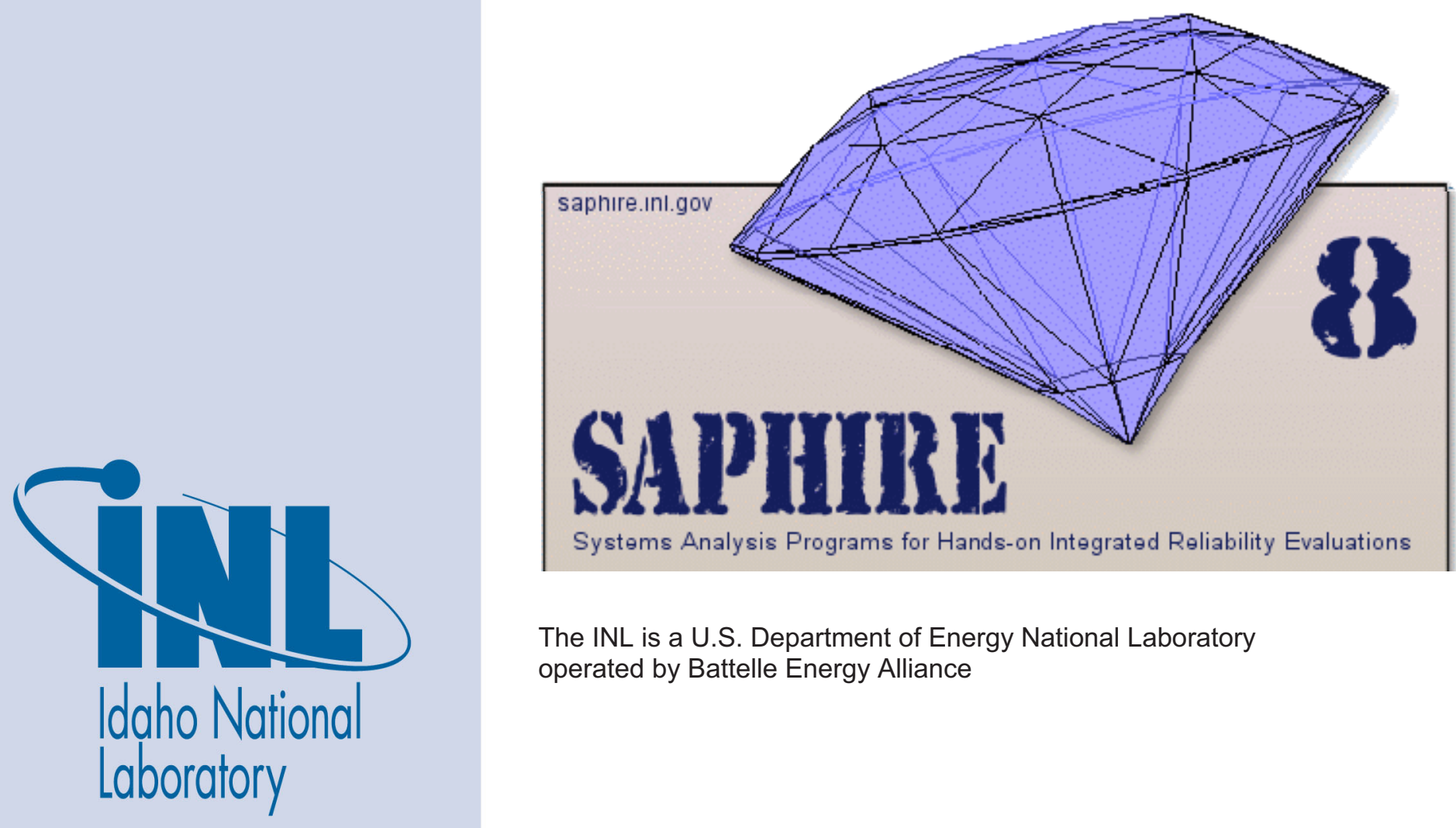

The INL is a U.S. Department of Energy National Laboratory operated by Battelle Energy Alliance 


\title{
Software Verification and Validation Plan Activities, 2011 - SAPHIRE 8 Quality Assurance
}

Kurt G. Vedros

Curtis L. Smith

September 2011

\begin{abstract}
Idaho National Laboratory
Idaho Falls, Idaho 83415
\end{abstract}

http://www.inl.gov

Prepared for the

U.S. Nuclear Regulatory Commission

Washington, DC 20555

Project No. V6059 


\section{Table of Contents}

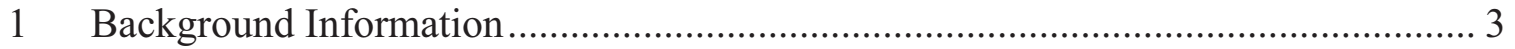

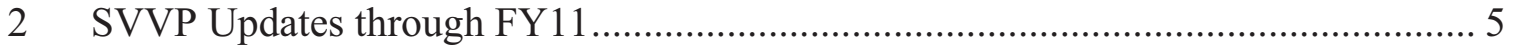

3 SVVP Review, Recommendations .................................................................... 5

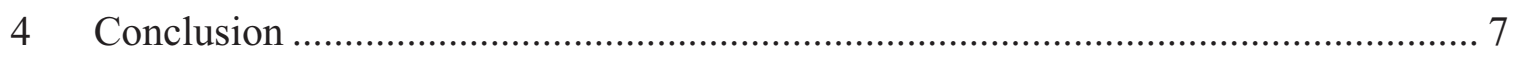




\section{Background Information}

The Software Verification and Validation Plan for SAPHIRE 8 are split into two volumes. Volume 1 includes the design requirements for the initial release of SAPHIRE 8 all the way through the most recent major design requirement for PRIB. Volume 2 includes the verification and validation approach, test specifications, test phases, environment, and software coding standards agreed to for Modula-2 and Delphi modules. Volume 2 also includes a copy of the Requirements Traceability Matrix (RTM), which is maintained online.

The requirements in the RTM are derived from the design documents also presented within the SVVP. Existing tests that are assigned to these requirements are listed in the SVVP and any additional tests deemed necessary throughout development are also placed in the SVVP and the RTM. In this way, the SVVP and RTM are interrelated, when one is modified, the other is as well.

The SVVP acts as both a record of development, verification and validation and also as a roadmap for $\mathrm{V} \& \mathrm{~V}$ moving forward.

Viewing the SVVP contents all in outline form gives one a good idea of the scope it provides:

- SVVP Volume I

- Introduction and Overview

- Software Requirements

- Graphical User Interface (GUI)

- Application Program Interface (API) Requirements

- Database Requirements

- Core Modeling Requirements

- Core Analysis Requirements

- Embedded Macro Requirements

- Phase Definition Requirements

- External Events Requirements

- Conceptual Model Editor Requirements

- Interface Requirements and Specifications

- GUI Requirements

- API Requirements

- Database Interfaced Requirements

- Core Modeling Interface Requirements

- Embedded Macro Interface Requirements

- Phase Missions Interface Requirements

- External Events Model Interface Requirements

- Conceptual Model Graphical Editor Interface Requirements

- Operating System Interface Requirements 
○ Design Specification

- GUI Design

- API Design

- Database Detailed Design

- Core Modeling Design

- Core Analysis Design

- Embedded Macro Design

- Phase Mission Design

- Common Cause Failure Module Design

- External Events Design

- Level 2 Design

- SDP Workspace Design

- Events and Condition Assessment Workspace Design

- Convergence Solving Design

- Time Based Convolution

- Inspection Planning Report Specification

- Analysis Speed Improvements

- SVVP Volume II

○ V\&V Approach

- Project Background and Objectives

- Project Scope and Organization

- Quality Assurance and Assessment Approach

- Software Releases

- Change Design and Testing Procedure

- Test Specification

- Features to be Tested

- User-Interface Testing

- Features Not Tested

- Test Methodologies

- Background

- Testing Approach

- Test Data

- Test Documents

- Requirements Validation

- Test Control Procedures

- Test Phases

- Test Design of the Automated Test Suite

- Participants

- Sources of Data

- Entrance and Exit Criteria 
- Requirements

- Work Products

- Development and Test Environment

- Hardware Platform

- Software Platform

- Staffing and Training

- Test Summary

- Modula-2 Coding Standard

- Delphi Coding Standard

- Requirements Traceability Matrix

- IEEE Verification and Validation Integrity Level 1 Tasks and SAPHIRE 8 Development Compliance

- Database Schema for SAPHIRE 8

- API Module Unit Summaries and List of External Procedure Calls

\section{SVVP Updates through FY11}

An official update was released in February 2011. This update was to add a new automated test, to revise the SVVP wording to indicate the operational life cycle that SAPHIRE 8 has entered, and to provide design documentation for Inspection Planning Reports (which evolved into the) and Analysis Speed Improvements.

In September 2011, the SVVP is updated to include the following: the two new automated tests, the inclusion of metrics into the testing regime and references to the addition of the Preliminary Design Review and Critical Design Review processes, design documentation for the Plant Risk Information e-Book (PRIB) and the Cut Set Editor improvements. The most recent information full RTM was also included in volume 2 .

\section{SVVP Review, Recommendations}

The SVVP structure lends itself to the addition of new design features, tests, and coding standards. Maintenance of the document keeps it both relevant and useful as a reference for the latest state of the SAPHIRE project's verification and validation actions and as a record of prior actions. Its current structure is a result of the IV\&V team input and review. No major changes to the SVVP layout were considered necessary at this time. The appropriate sections were updated with new information and processes as they were developed over the past year. 
A lesson learned from the initial SAPHIRE 8 IV\&V effort was that metrics can play a major role in maintaining and improving quality. A review of the metrics used in the IV\&V and others available was performed by the SQA. The use of metrics as a development tool and quality assurance tool was discussed with the design team which helped to determine which metrics from the IV\&V should be dropped, continued or added.

As a development tool, metrics such as complexity measures can be used to point out modules that can be more efficient, thus improving the speed of the program once the complexity is addressed. The complexity being measured is where the code runs with as few loops as possible and is not a measure of complexity that the operator experiences through the interface of the program, which it was considered best to capture using a bugs and new features request trending metric.

A process was added to the SVVP to incorporate the metrics chosen as a measure of quality. The software metrics include coverage, memory and thread validation, performance validation, and module complexity ratings. Also, in response to the IV\&V suggestion, in addition to the software driven metrics the metric of bug tracking for trends was added to the SVVP.

Another improvement to the SVVP process, and therefore the document, is the formalization of the Preliminary Design Review and Critical Design Review. This refines the process from the ad hoc way in which it was performed in the past. Now that there is a standard way of performing these reviews the customer and the design team will be better informed of the status of design feature development. The SV\&V now holds references to these two documents.

The PDR and CDR process now has these steps:

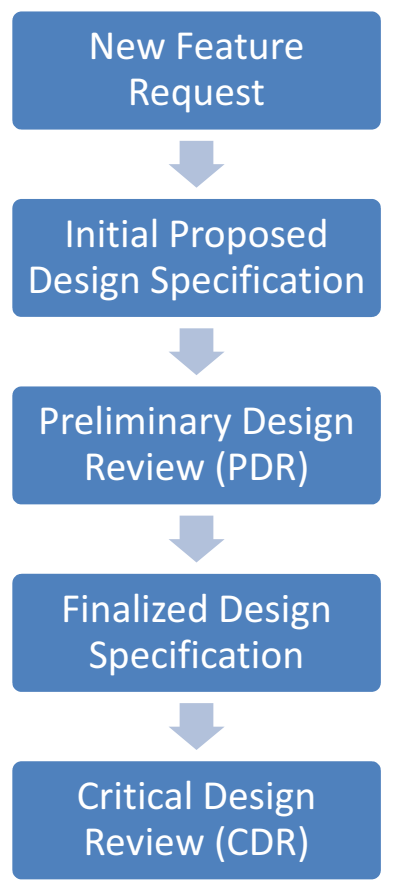


Review procedures and documentation are similar for the PDR and CDR. The PDR signature table and procedure is listed below.

If multiple PDRs are required for acceptance, save the signature table and documentation and add the next PDR.

\begin{tabular}{|l|l|l|l|l|}
\hline \multicolumn{5}{|c|}{ Preliminary Design Review \# 1 } \\
\hline \multicolumn{1}{|c|}{ Reviewer } & Name & Date & $\begin{array}{c}\text { Appraisal } \\
\text { Status* }\end{array}$ & \multicolumn{1}{c|}{$\begin{array}{c}\text { Notes } \\
\text { (Explain status if necessary }\end{array}$} \\
\hline $\begin{array}{l}\text { NRC Technical } \\
\text { Staff }\end{array}$ & & & \\
\hline $\begin{array}{l}\text { SAPHIRE Project } \\
\text { Principal } \\
\text { Investigator or } \\
\text { other Key }\end{array}$ & & & \\
Personnel & & & & \\
\hline $\begin{array}{l}\text { SAPHIRE Project } \\
\text { Software Quality }\end{array}$ & & & & \\
Assurance & & & \\
Personnel & & & & \\
\hline * Appraisal Status: 1=Accepted as is, 2=Accepted with minor modifications, 3=Rejected \\
\hline
\end{tabular}

Documentation: List emails, phone conversations, etc... that document the appraisal status of the design by the reviewers.

\section{Conclusion}

The SV\&V Plan experienced changes over the past year to bring it into the operational software life cycle of SAPHIRE 8 and to maintain its sections on design features and new tests added. Two additions to the SVVP were the addition of metrics and the PDR and CDR processes. The SVVP is considered to be an up to date reference and useful roadmap of verification and validation activities going forward. 